\title{
Biphasic Catalysis in Aqueous and Ionic Liquid Media
}

\author{
Céline Fellay§* \\ §CS Poster Prize Winner
}

\begin{abstract}
An overview of recent developments from the Laboratory of Organometallic and Medicinal Chemistry at the EPFL in biphasic catalysis, involving aqueous solutions and ionic liquids, and in $\mathrm{CO}_{2}$ reduction is presented. Progress in the use of ionic liquids, either by catalyst modification or by the design of task-specific ionic liquids is described. The application of high pressure methods to provide fundamental data and mechanistic insights into reactions and processes in these solvents is also described.
\end{abstract}

Keywords: Aqueous $\mathrm{CO}_{2}$ reduction · Biphasic catalysis · High pressure chemistry · Ionic liquids . Ruthenium hydrides

\section{Introduction}

These days environmental considerations are an essential part of chemical process development. The reduction of the use of volatile organic compounds such as solvents, together with improvements in sustainability and recyclability are among the key objectives to minimise the impact of chemical industry on the environment. [1] Biphasic catalysis is a well-developed research area that has an impact on such goals. In biphasic processes a catalyst is immobilised in one phase and the product(s), in another phase, are easily separated such that the catalyst phase can be recycled. The Shell Higher Olefin Process ${ }^{[2]}$ and the Rhône-PoulencRuhrchemie hydroformylation process ${ }^{[3]}$ are industrial examples based on this concept. Water has advantages like non-toxicity and abundance which make it a medium of choice for biphasic catalysis, but also to potentially replace organic solvents completely. Many reactions have been successfully performed in aqueous solution, ${ }^{[4]}$ however many organometallic catalysts are not soluble in water or decompose in its presence. Furthermore, low solubility of some organic compounds in water can impede reaction rates and yields. Because of these drawbacks, alternative media for biphasic catalysis, such as ionic liquids, supercritical fluids and fluorous solvents, are under investigation.

Because of the relatively low solubility of some gases $\left(\mathrm{H}_{2}, \mathrm{CO}\right)$ in water and ionic liquids, it is advantageous to work under pressure. ${ }^{[5]}$ High-pressure techniques also provide useful fundamental and mechanistic information, but require in situ and non-destructive analytical methods. Our laboratories have contributed to the development of these techniques (e.g. NMR, FTIR, UV-visible, flow methods, etc. $)^{[6]}$ and have applied them successfully in reaction mechanism investigations. ${ }^{[7]}$

\section{Ionic liquids}

Ionic liquids are often referred to as 'green' because of their low vapour pressure. A wide range of ionic liquids are known and since they can be immiscible with organic compounds and/or water, and many metal catalysts, organic substrates and gases are soluble in them, they are of particular interest for biphasic catalysis. ${ }^{[8]}$
Nevertheless, ionic liquids also have their own problems, one of them being purity, notably traces of halide impurities resulting from their synthesis are extremely difficult to remove and can coordinate to the transition metal centres, leading to deactivation of the catalyst. ${ }^{[9]}$ Chloride anions are poorly solvated in ionic liquids and therefore exhibit a higher nucleophilicity than in water, as rationalised by Daguenet and Dyson for imidazolium-based ionic liquids. ${ }^{[10]}$ For this reason, chloride dissociation from a transition-metal complex might be inhibited in ionic liquids and in cases where chloride dissociation is a crucial step for the formation of the catalytic active species then catalytic activity might be suppressed. This was illustrated with the study of the activity of ruthenium(II)- $p$-cymene complexes in styrene hydrogenation. ${ }^{[10]}$ The complex 1 (Fig. 1) catalyses styrene hydrogenation in aqueous biphasic system via dissociation of the chloride to allow coordination of dihydrogen. ${ }^{[11]}$ Complexes 1 and 2 (Fig. 1, where the chloride counter-anion of $\mathbf{1}$ has been exchanged with triflate), exhibit no activity in the chloride-free 1-butyl-3-methylimidazolium triflate $[\mathrm{bmim}]\left[\mathrm{O}_{3} \mathrm{SCF}_{3}\right]$. Substitution of the chloride ligand by the more

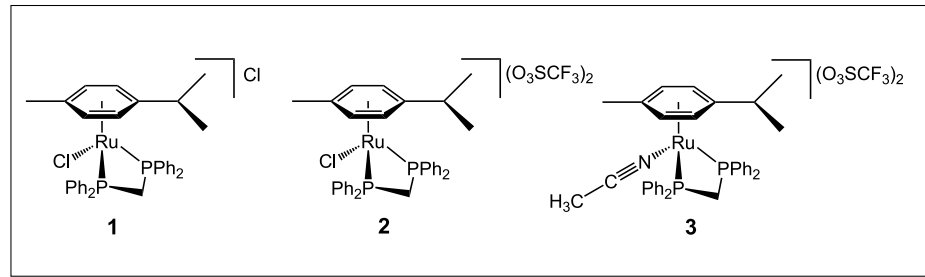

Fig. 1. Structures of ruthenium(II) $\eta^{6}-p$-cymene dppm derivatives 1-3 
labile and neutral acetonitrile ligand affords 3, which exhibits high activity in the ionic liquid. Addition of water as a cosolvent in the ionic liquid facilitates chloride dissociation and catalysis may occur.

As outlined above, catalyst stability and retention is essential to the development of sustainable processes. While ionic transition-metal catalysts are generally well retained in the ionic liquid phase during product separation, uncharged catalysts tend to be lost to the product phase. A common way to prevent catalyst leaching is by modification of the ligands with charged moieties. A variety of phosphine ligands bearing charged groups have been successfully used for catalysis in ionic liquids with an increased retention of the catalyst. ${ }^{[8]}$ However, phosphine ligand modification is not always straightforward and derivatisation of chiral phosphines, for example, has a detrimental effect on enantioselectivity. In this context, we recently prepared imidazolium-tagged ruthenium(II)-arene complexes (Fig. 2) and showed they were active in biphasic catalysis. ${ }^{[12,13]}$ For the asymmetric transfer-hydrogenation of aryl ketones, the presence of the imidazolium group on the arene demonstrated a considerable reduction of catalyst leaching, without affecting the enantioselectivity. ${ }^{[12]}$ Hydrogenation of styrene in an ionic liquid-organic biphasic system has also been performed with this new type of functionalised catalyst. ${ }^{[13]}$ Since these metal complexes are also water soluble, aqueous-organic biphasic catalysis was also studied for comparison. Catalytic activities appeared to be higher for the biphasic system containing water than that with ionic liquid; although less leaching occurred when the catalyst was immobilised in the ionic liquid phase.

Similarly, ruthenium benzo-crown ether complexes have been prepared and used for enantioselective transfer-hydrogenation of acetophenone, ${ }^{[14]}$ with complexation of different alkaline metals within the crown influencing both selectivity and reaction rate. The idea is to tune the solubility of the catalyst by complexation of cations to the crown and hence having 'phase-changing' catalysts, extending the immobilisation concept described above.

Another strategy to improve catalyst immobilisation in ionic liquids is by functionalising the ionic liquid with a coordinating group instead of derivatising the transition metal catalyst. Several of these so-called 'task-specific ionic liquids', with functional groups such as amines, amides, ethers, alcohols, acids, as well as urea, thiourea and fluorous chains, are known. ${ }^{[15]} \mathrm{Re}$ cently, our group reported nitrile-functionalised ionic liquids showing very promising catalyst retention results. Such ionic liquids were successfully used in hydrogenation reactions, ${ }^{[16]}$ as well as for carbon-carbon

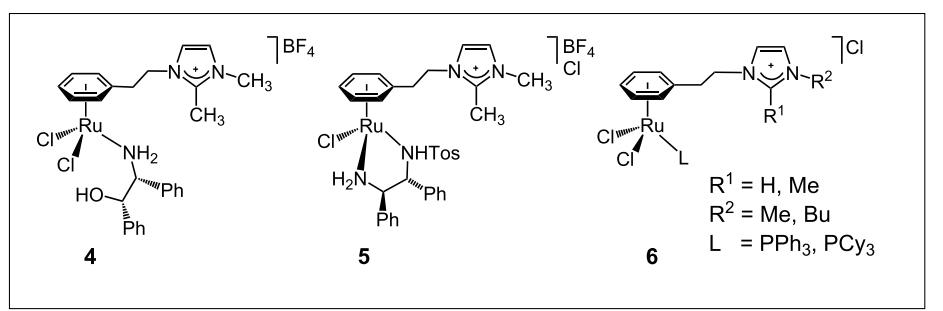

Fig. 2. Imidazolium-tagged ruthenium(II)-arene complexes used for biphasic catalysis in ionic liquids, $\mathbf{4}$ and $\mathbf{5}$ for transfer-hydrogenation, $\mathbf{6}$ for styrene hydrogenation

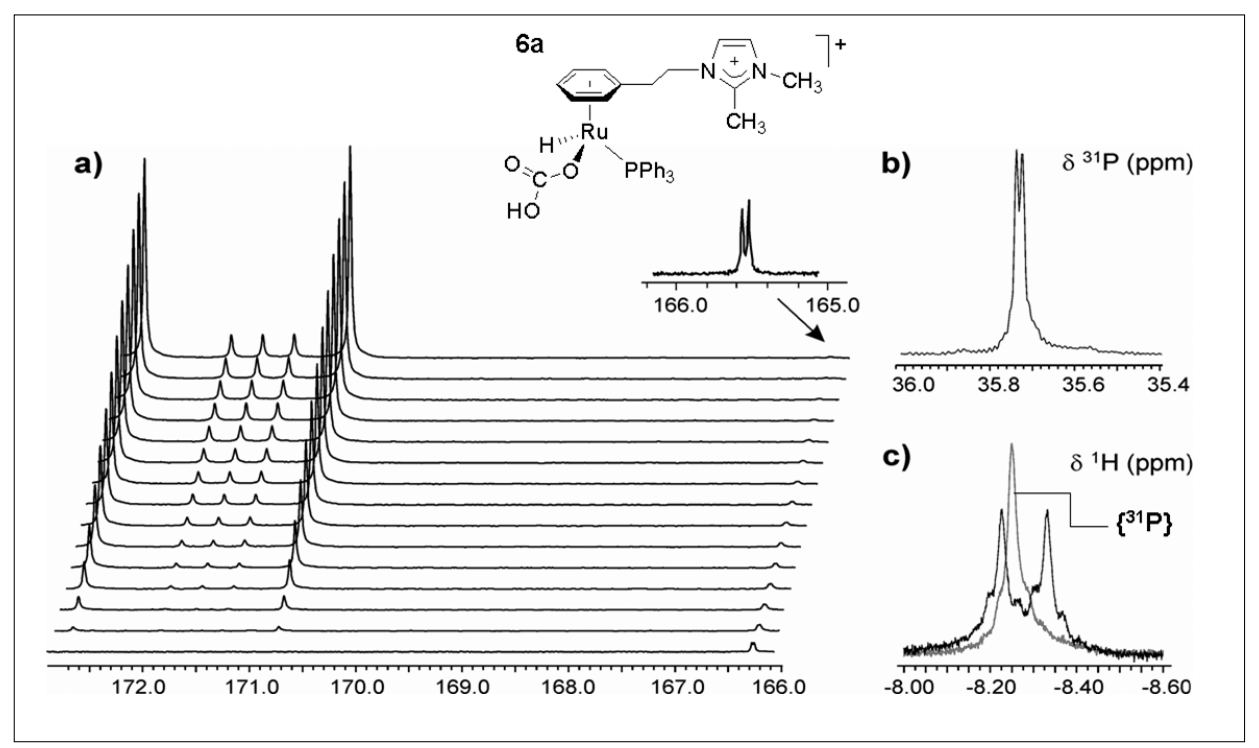

Fig. 3. Bicarbonate-hydride intermediate 6a proposed from NMR evidence a) evolution of the ${ }^{13} \mathrm{C}$ NMR signals stemming from formate $\left[\mathrm{H}^{13} \mathrm{COO}\right]^{-}\left(\delta=171.7 \mathrm{ppm},{ }^{1} J_{\mathrm{CH}}=194 \mathrm{~Hz}\right)$, deuterated formate [DC $^{13} \mathrm{OO}^{-}\left(\delta=171.6 \mathrm{ppm},{ }^{1} J_{\mathrm{CD}}=30 \mathrm{~Hz}\right)$ and the intermediate bicarbonate complex $(\delta=166.0 \mathrm{ppm}$, $\left.{ }^{3} J_{\mathrm{PC}}=2.4 \mathrm{~Hz}\right)$, b) ${ }^{31} \mathrm{P}\left\{{ }^{1} \mathrm{H}\right\}$ NMR spectrum $\left.\left(\delta=35.7 \mathrm{ppm},{ }^{3} J_{\mathrm{CP}}=2.4 \mathrm{~Hz}\right), \mathrm{c}\right){ }^{1} \mathrm{H}$ NMR spectrum of the hydride region $\left(\delta=-8.25 \mathrm{ppm},{ }^{2} J_{\mathrm{PH}}=42 \mathrm{~Hz}\right)$.

coupling reactions, ${ }^{[17]}$ showing particularly good catalyst stability and retention. In the case of the Stille reaction, evenly distributed palladium nanoparticles were observed. It is likely that the nitrile-functionalised group interacts with the surface of the nanoparticles, ${ }^{[18]}$ thus preventing agglomeration and hence suppressing catalyst deactivation.

\section{Carbon Dioxide Reduction}

Due to the high abundance of $\mathrm{CO}_{2}$ it has become a very interesting potential $\mathrm{C} 1$ building block in recent years. Hydrogenation of $\mathrm{CO}_{2}$ into useful products such as formic acid, methanol, etc. has been extensively studied.[19] Despite the relative lack of reactivity of $\mathrm{CO}_{2}$, it has been successfully hydrogenated in organic solvents, ${ }^{[19 a]}$ in aqueous solutions, ${ }^{[20]}$ in supercritical $\mathrm{CO}_{2}{ }^{[21]}$ and more recently in ionic liquids. ${ }^{[22]}$ Although the highest activity has been obtained in supercritical $\mathrm{CO}_{2}$, good performances can be obtained in aqueous solutions. By using a mixture of $\mathrm{CO}_{2}$, bicarbonate and carbonate, the $\mathrm{pH}$ can be tuned so that $\mathrm{CO}_{2}$ can be reduced by catalysts in the absence of additives like amine or alcohol.[20]

Since $\mathrm{Ru}(\mathrm{II})$-arene piano-stool complexes containing water-soluble phosphine ligands, originally developed for medicinal applications, ${ }^{[23]}$ have been successfully used in $\mathrm{CO}_{2}$ hydrogenation in aqueous solution,[24] the imidazolium-tagged ruthenium(II)-arene complexes 6 (Fig. 2) were also tested. ${ }^{[13]}$ They showed lower activity than $\left[\mathrm{Ru}\left(\eta^{6}\right.\right.$-arene $) \mathrm{Cl}_{2}$ (pta) $]$ (arene = benzene, $p$-cymene), where the hydrophilic phosphine pta provides the water solubility of the compound, instead of having a hydrophilic imidazolium functionalised arene. ${ }^{[24]}$ Ruthenium bicarbonate-hydride complexes have previously been proposed as intermediates in $\mathrm{CO}_{2}$ hydrogenation, without being directly identified. ${ }^{[25]} \mathrm{Be}-$ cause of the relatively low activity of complexes 6, such an intermediate (complex 6a) was directly identified by NMR spectroscopy (Fig. 3), albeit only partially characterised.

Unequivocal in situ characterisation of such an intermediate has been achieved very recently, ${ }^{[26]}$ using a related nonorganometallic piano-stool compound 
$\left[\mathrm{RuCl}_{2}(\mathrm{pta})\left([9] \mathrm{aneS}_{3}\right)\right] \quad(\mathrm{pta}=1,3,5$-triaza7-phosphaadamantane, [9]ane $\mathrm{S}_{3}=1,4,7$ trithiacyclononane), originally developed by Alessio and coworkers for medicinal purposes. ${ }^{[27]}$ In this case again, the activity of the catalyst for the $\mathrm{CO}_{2}$ hydrogenation is also rather low, facilitating the characterisation of the intermediate species as a ruthenium bicarbonate-hydride species (complex 7, Fig. 4). Although unambiguous distinction between a carbonate and bicarbonate species is not possible from the available data, according to literature evidence, ${ }^{20]}$ bicarbonate is most likely. Since in both cases, no other intermediate species are observed, it can be assumed that $\mathrm{CO}_{2}$ reduction takes place via a hydrido-bicarbonate species and that the rate-determining step is intramolecular hydride transfer from the metal to the complexed bicarbonate. This mechanism is consistent with recently published theoretical studies. ${ }^{[28]}$

\section{Conclusions}

Different aspects of biphasic catalysis have been illustrated with selected examples of on-going research in this area from our group. Functionalisation of ionic liquids appears to be a particularly attractive method to improve catalyst immobilisation, although progress in more traditional methods like catalyst modification also exhibit promising results. Finally reaction intermediates in the extensively studied $\mathrm{CO}_{2}$ reduction in aqueous phase have been proposed, based on multinuclear NMR spectroscopic data. Such information provides new leads for the rational design of new catalysts.

\section{Acknowledgements}

The Swiss National Science Foundation is gratefully acknowledged for financial support, and Gábor Laurenczy and Paul J. Dyson for helpful discussions.

Received: December 18, 2006

[1] R. A. Sheldon, Green Chem. 2005, 7, 267.

[2] E. R. Freitas, C. R. Gum, Chem. Eng. Prog. 1979, 73-76.

[3] a) E. Kuntz, Fr. Pat. 2314910; b) B. Cornils, J. Mol.Cat. A 1999, 143, 1.

[4] 'Aqueous-phase organometallic catalysis, concepts and applications', Eds. B. Cornils, W. A. Herrmann, Wiley-VCH, Weinheim, 1998.

[5] a) P. J. Dyson, G. Laurenczy, C. A. Ohlin, J. Vallance, T. Welton, Chem. Commun. 2003, 19, 2418; b) C. A. Ohlin, P. J. Dyson, G. Laurenczy, Chem. Commun. 2004, 9, 1070.

[6] a) P. Bugnon, G. Laurenczy, Y. Ducommun, P.-Y. Sauvageat, A. Merbach, R. Ith, R. Tschanz, M. Doludda, R. Bergbauer, E. Grell, Anal. Chem. 1996, 68, 3045; b)

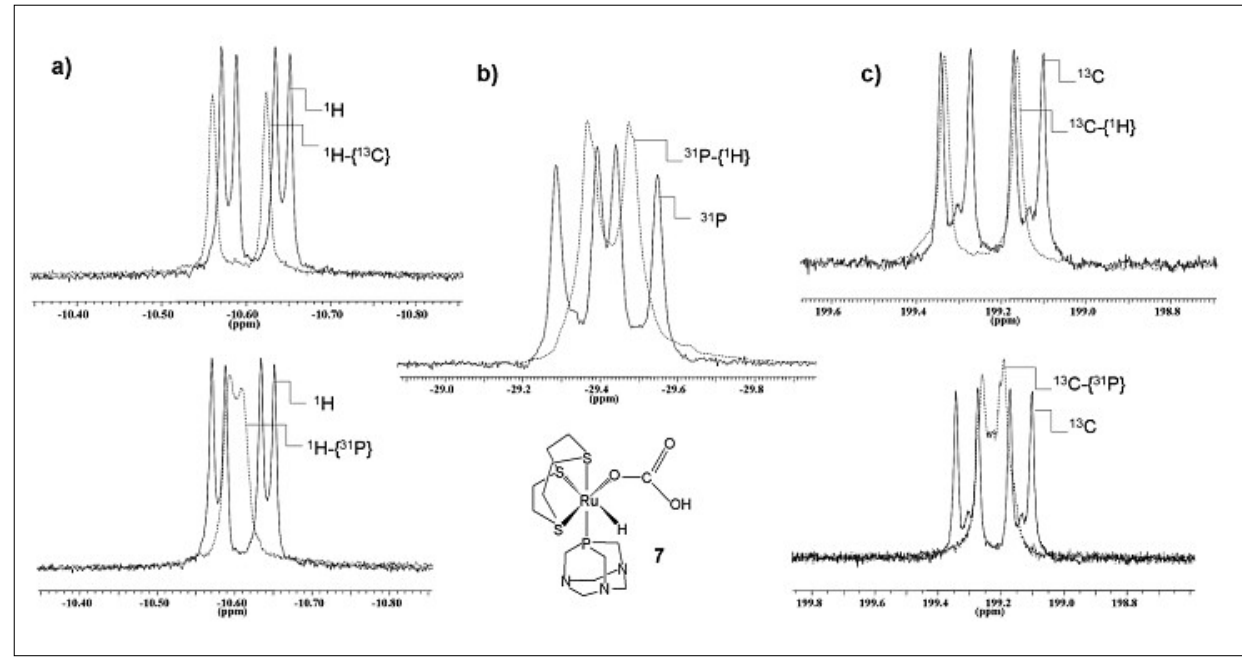

Fig. 4. Bicarbonate-hydride intermediate 7, characterised in situ by NMR: a) ${ }^{1} \mathrm{H}$ NMR, $\delta=-10.6 \mathrm{ppm}$, $\left.\left.{ }^{2} J_{\mathrm{PH}}=25 \mathrm{~Hz} ;{ }^{3} \mathrm{~J}_{\mathrm{CH}}=7 \mathrm{~Hz}, \mathrm{~b}\right){ }^{31} \mathrm{P} \mathrm{NMR}, \delta=-29.4,{ }^{2} J_{\mathrm{PH}}=25 \mathrm{~Hz}, \mathrm{c}\right){ }^{13} \mathrm{C}$ NMR, $\delta=199.2 \mathrm{ppm},{ }^{3} J_{\mathrm{PC}}=$ $17 \mathrm{~Hz} ;{ }^{3} J_{\mathrm{CH}}=7 \mathrm{~Hz}$.

G. Laurenczy, F. Lukács, R. Roulet, Analytica Chimica Acta 1998, 359, 275; c) G. Laurenczy, L. Helm, in 'Catalytic Mechanisms from Spectroscopic Measurements', Ed. B. Heaton, Wiley-VCH Verlag, Weinheim, 2005, p. 81.

[7] a) A. B. Chaplin, C. Fellay, G. Laurenczy, P. J. Dyson, Organometallics, 2007, 26, 586; b) A. Vidis, G. Laurenczy, E. Küsters, G. Sedelmeier, P. J. Dyson, J. Phys. Org. Chem., in press.

[8] T. J. Geldbach, P. J. Dyson, 'Metal Catalysed Reactions in Ionic Liquids, Catalysis by Metal Complexes', Vol. 29, Springer, Dodrecht, 2005.

[9] a)Y. Chauvin, L. Mussman, H. Olivier, Angew. Chem. Int. Ed. Engl. 1995, 34, 2698; b) P. J. Dyson, D. J. Ellis, W. Henderson, G. Laurenczy, Adv. Synth. Catal. 2003, 345, 216.

[10] a) C. Daguenet, P. J. Dyson, Organometallics 2004, 23, 6080; b) C. Daguenet, P. J. Dyson, Organometallics 2006, 25, 5811.

[11] C. Daguenet, R. Scopelliti, P. J. Dyson, Organometallics 2004, 23, 4849.

[12] T. J. Geldbach, P. J. Dyson, J. Am. Chem. Soc. 2004, 126, 8114.

[13] T. J. Geldbach, G. Laurenczy, R. Scopelliti, P. J. Dyson, Organometallics 2006, 25 , 733.

[14] T. J. Geldbach, M. R. H. Brown, R. Scopelliti, P. J. Dyson, J. Organomet. Chem. 2005, 690, 5055.

[15] Z. Fei, T. J. Geldbach, D. Zhao, P. J. Dyson, Chem. Eur. J. 2006, 12, 2122.

[16] D. Zhao, Z. Fei, R. Scopelliti, P. J. Dyson, Inorg. Chem. 2004, 43, 2197.

[17] a) D. Zhao, Z. Fei, T. J. Geldbach, R. Scopelliti, P. J. Dyson, J. Am. Chem. Soc. 2004, 126, 15876; b) C. Chiappe, D. Pieraccini, D. Zhao, Z. Fei, P. J. Dyson, $A d v$ Synth. Catal. 2006, 348, 68; c) D. S. Reddy, D. Zhao, Z. Fei, C. M. Rao Volla, P. J. Dyson, P. Vogel, Synlett 2006, 3155.
[18] P. J. Dyson, Chimia 2005, 59, 66.

[19] Selected reviews: a) P. G. Jessop, T. Ikariya, R. Noyori, Chem. Rev. 1995, 95, 259; b) W. Leitner, Angew. Chem. Int. Ed. Engl. 1995, 34, 2207; c) P. G. Jessop, F. Joó, C.-C. Tai, Coord. Chem. Rev. 2004, 248, 2425.

[20] a) G. Laurenczy, F. Joó, L. Nádasdi, Inorg. Chem. 2000, 39, 5083; b) F. Joó, G. Laurenczy, L. Nádasdi, J. Elek, Chem. Commun. 1999, 971.

[21] a) P. G. Jessop, T. Ikariya, R. Noyori, $\mathrm{Na}$ ture 1994, 368, 231; b) P. G. Jessop, Y. Hsiao, T. Ikariya, R. Noyori, J. Am. Chem. Soc. 1996, 118, 344.

[22] a) F. Liu, M. B. Abrams, R. T. Baker, W. Tumas, Chem. Commun. 2001, 433; b) C. A. Ohlin, G. Laurenczy, High Pressure Res. 2003, 23, 239.

[23] a) C. S. Allardyce, P. J. Dyson, D. J. Ellis, S. L. Heath, Chem. Commun. 2001, 1396; b) C. Scolaro, A. Bergamo, L. Brescacin, R. Delfino, M. Cocchietto, G. Laurenczy, T. J. Geldbach, G. Sava, P. J. Dyson, $J$. Med. Chem. 2005, 48, 4161.

[24] H. Horváth, G. Laurenczy, A. Kathó, J. Organomet. Chem. 2004, 689, 1036.

[25] J. Elek, L. Nádasdi, G. Papp, G. Laurenczy, F. Joó, Appl. Catal. A 2003, 255, 59.

[26] G. Laurenczy, S. Jedner, E. Alessio, P. J. Dyson, Inorg. Chem. Commun. 2007, 10, 558.

[27] B. Serli, E. Zangrando, T. Gianferrara, C. Scolaro, P. J. Dyson, A. Bergamo, E. Alessio, Eur. J. Inorg. Chem. 2005, 17, 3423.

[28] a) Y.-Y. Ohnishi, T. Matsunaga, Y. Nakao, H. Sato, S. Sakaki, J. Am. Chem. Soc. 2005, 127, 4021; b) Y.-Y. Ohnishi, Y. Nakao, H. Sato, S. Sakaki, Organometallics 2006, 25, 3352; c) G. Kovács, G. Schubert, F. Joó, I. Pápai, Catal. Today 2006, 115 , 53. 